\title{
Latent Cytomegalovirus Infection in Female Mice Increases Breast Cancer Metastasis
}

Zelei Yang ${ }^{1,2,3}$, Xiaoyun Tang ${ }^{1,2,3}$, Guanmin Meng 1,2,3, Matthew G. K. Benesch ${ }^{1,2,3,4} \mathbb{D}_{\text {, }}$ Martina Mackova ${ }^{3,5}$, Ana Paula Belon 3,5 ${ }^{-}$, Jesus Serrano-Lomelin ${ }^{3,5}$, Ing Swie Goping 1,2,3,6, David N. Brindley ${ }^{1,2,3, *}$ and Denise G. Hemmings $2,3,5,7, *$

1 Department of Biochemistry, University of Alberta, Edmonton, AB T6G 2S2, Canada; zelei@ualberta.ca (Z.Y.); xtang2@ualberta.ca (X.T.); guanmin@ualberta.ca (G.M.); benesch@ualberta.ca (M.G.K.B.); igoping@ualberta.ca (I.S.G.)

2 Cancer Research Institute of Northern Alberta, Edmonton, AB T6G 2S2, Canada

3 Women and Children's Health Research Institute, Edmonton, AB T6G 2S2, Canada; mackova@ualberta.ca (M.M.); ana.belon@ualberta.ca (A.P.B.); jaserran@ualberta.ca (J.S.-L.)

4 Discipline of Surgery, Faculty of Medicine, Memorial University of Newfoundland, St. John's, NL A1C 5S7, Canada

5 Department of Obstetrics/Gynecology, University of Alberta, Edmonton, AB T6G 2S2, Canada

6 Department of Oncology, University of Alberta, Edmonton, AB T6G 1Z2, Canada

7 Department of Medical Microbiology and Immunology, University of Alberta, Edmonton, AB T6G 2S2, Canada

* Correspondence: david.brindley@ualberta.ca (D.N.B); dghemmin@ualberta.ca (D.G.H.); Tel.: +1-780-492-2078 (D.N.B.); +1-780-492-2098 (D.G.H.)

Received: 10 January 2019; Accepted: 26 March 2019; Published: 29 March 2019

\begin{abstract}
Cytomegalovirus (CMV) infects $40-70 \%$ of women, but infection has been reported in $>95 \%$ of breast cancer patients. We investigated the consequences of these observations by infecting mice with mCMV or a negative control medium for 4 days, 11 days or 10 weeks to establish active, intermediate or latent infections, respectively. Syngeneic 4T1 or E0771 breast cancer cells were then injected into a mammary fat pad of BALB/c or C57BL/6 mice, respectively. Infection did not affect tumor growth in these conditions, but latently infected BALB/c mice developed more lung metastases. The latent mCMV infection of MMTV-PyVT mice, which develop spontaneous breast tumors, also did not affect the number or sizes of breast tumors. However, there were more tumors that were multilobed with greater blood content, which had enhanced vasculature and decreased collagen content. Most significantly, mCMV infection also increased the number and size of lung metastases, which showed a higher cell proliferation. Viral DNA was detected in breast tumors and lung nodules although viral mRNA was not. These novel results have important clinical implications since an increased metastasis is prognostic of decreased survival. This work provides evidence that treating or preventing HCMV infections may increase the life expectancy of breast cancer patients by decreasing metastasis.
\end{abstract}

Keywords: angiogenesis; collagen; glycoprotein B; interleukins; tumor growth

\section{Introduction}

Breast cancer is the most common malignancy among women, and our inability to treat metastasis is a major cause of mortality. The net 5 -year survival rates are $87 \%$ for all patients diagnosed with breast cancer, but once the tumors metastasize, the survival rate decreases dramatically to $22 \%$ [1]. It is, therefore, vital to develop new strategies for preventing metastasis and for treating metastatic cancer to decrease mortality. 
This study concentrates on the role of cytomegalovirus (CMV) infection on breast tumor growth and metastasis. Human CMV (HCMV) is a $\beta$-herpesvirus of the Herpesviridae family, and it produces lifelong infections [2]. Forty to $70 \%$ of the adult population is infected by HCMV in developed countries, and this rate increases to approx. $85-90 \%$ when people reach $75-80$ years of age [3,4]. In fact, it has been hypothesized that the response to infection with this virus depends on the age at initial exposure, with a late exposure causing an increased risk of breast cancer [5].

HCMV infection normally causes no noticeable symptoms in immunocompetent individuals [6]. After entry into susceptible cells, HCMV produces viral proteins in three stages: immediate early (IE), early and late [7]. At each stage, these viral proteins have essential roles in establishing a productive HCMV infection. IE proteins are important for transcription regulation, early proteins are important for viral replication and late proteins are important for the assembly of new viral particles [8]. A strong innate immune response is produced during the initial HCMV infection. This is followed by an adaptive response, and both are important in the host's defense against HCMV [9]. Once the initial infection is resolved, CMV enters a latent state where the viral genome is retained in the host with a restricted expression of viral genes [10]. In contrast to the initial active infection where virus replication is high, replication in chronic and presumed latent infections is at low subclinical levels, if present at all [11]. In fact, this latent state has been described as symbiotic since it can confer immune benefits to the host against other infections $[12,13]$.

A reactivation to full virus replication can occur during inflammation and stress in the aging population and in immunocompromised hosts including organ transplant recipients undergoing immunosuppressive therapies [14-17]. This reactivation of HCMV infection can be life-threatening, especially in immunocompromised or critically ill patients [18].

Increasing evidence shows that HCMV infection could play a role in breast cancer $[19,20]$. It has been reported that $95 \%$ of women with breast cancer are HCMV-infected with a detection of viral DNA and/or proteins in breast tissues, whereas only approx. 70\% of non-neoplastic women are infected [21]. Several groups support a high detection of HCMV infection in women with breast cancer and the evidence of HCMV being present in breast tumors [22,23]. HCMV proteins and DNA are abundantly expressed in sentinel lymph nodes [24] and in brain tissue [25] from breast cancer patients, suggesting that HCMV might be associated with invasiveness and metastasis. HCMV positivity is also related to a poor overall survival and a low, relapse-free survival in breast cancer patients [26].

We conducted preclinical studies to interpret these findings and to understand the consequences of mouse CMV (mCMV) infection on the progression of breast cancer. We used three different mouse models of breast cancer to provide the first direct evidence that mCMV infection had only a minimal effect on breast tumor growth. However, mice with a presumed latent infection had increased numbers and sizes of lung metastases and enhanced cancer cell proliferation in the metastatic nodules. Latently infected MMTV-PyVT mice also developed breast tumors with enhanced angiogenesis and decreased collagen content, both of which could promote metastasis. Although mCMV DNA was detected in breast tumors and lung metastatic nodules from the latently infected mice, no active transcription of viral genes was detected in any of the tissues examined. These results from mouse models indicate that latent mCMV infection increases the metastasis of breast cancer cells to the lungs. This raises the possibility that HCMV infection in breast cancer patients could play a crucial role in increasing mortality from metastasis. If so, then preventing or controlling the negative consequences of an HCMV infection could provide a major improvement in breast cancer treatment and patient survival.

\section{Results}

\section{1. mCMV Infection Had Minimal Effect on Breast Tumor Growth in Mice}

We first demonstrated that an injection of the virus into mice from each mouse model produced an active infection by measuring the activity of $\beta$-galactosidase, a product of the Lac $Z$ gene, which was inserted into the IE-2 region of the mCMV genome. This modified virus has the same properties as 
native mCMV, but the production of $\beta$-galactosidase allows an active infection to be visualized by the conversion of its substrate, X-gal, into a blue product when the virus is actively replicating [27]. As an example, positive staining was observed in kidneys collected from C57BL/6 mice infected with active mCMV for 4 days but not in kidneys from mice injected with medium from which the virus was removed by filtration (FCMV; Figure S1a,b), UV-inactivated virus or PBS [28]. In addition, transcripts for mCMV IE-1/3 and a late viral product, glycoprotein B $(\mathrm{gB})$, were both detected in the salivary gland and kidney of mice actively infected for 4 days but not in control-treated mice [28]. The number of infected cells in kidneys as detected by $\beta$-galactosidase staining did not differ among models during active infection [28].

We then tested the effects of active, intermediate and latent mCMV infections on breast tumor growth. This was achieved by waiting 4 days, 11 days or 10 weeks, respectively, after treatment with $\mathrm{mCMV}$ or the control solutions before inoculating syngeneic $4 \mathrm{~T} 1$ breast cancer cells into a mammary fat pad of BALB/c mice or E0771 breast cancer cells into C57BL/ 6 mice. The volumes of the breast tumors in $\mathrm{mCMV}$-infected BALB/c mice were not significantly different throughout tumor development compared to the control-treated mice regardless of the timing of infection (Figure S2a,c,e). In the C57BL/ 6 mice, there were no differences in the tumor volume in those with an intermediate or latent infection; however, mice with an active infection prior to the injection of breast cancer cells had a reduced overall estimate of tumor volume on days 15 and 17, significant in post hoc testing (Figure $\mathrm{S} 2 \mathrm{~b}, \mathrm{~d}, \mathrm{f})$. The tumor volume is difficult to measure accurately, especially with fluid-filled tumors, and tumor mass measurements are normally more accurate.

With one exception, the masses of the breast tumors at the endpoint in the BALB/c or C57BL/6 models were not significantly different in the active or intermediate treatment groups between mCMV-infected or control-treated mice from either strain (Figure S3a-d) or in the latently infected mice (Figure 1). The exception was that latently infected BALB/c mice had an increased tumor mass compared to the PBS-treated group, but there was no significant difference compared to the control treatment where mCMV was inactivated by UV exposure (Figure 1a).

a) BALB/C

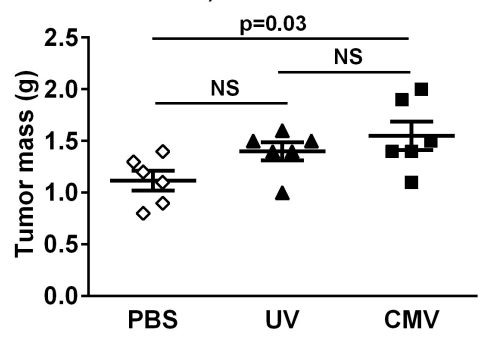

c) MMTV-PyVT

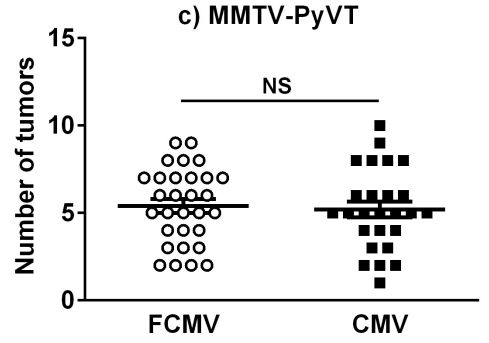

b) $\mathrm{C} 57 \mathrm{BL} / 6$

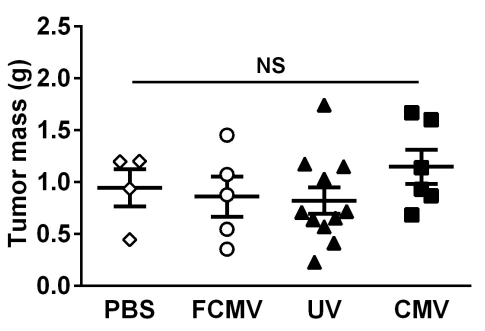

d) MMTV-PyVT

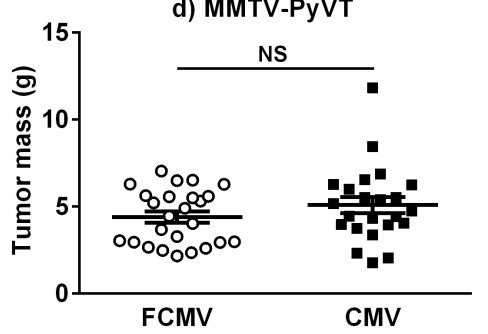

Figure 1. The latent mCMV infection has minimal effects on breast tumor mass. The breast tumor mass was measured at the endpoint in the latent infection models of BALB/c (a) and C57BL/6 (b) mice, $n$ $=6$ and $n=4-11$, respectively. The control mice were injected with PBS, UV-inactivated CMV (UV) or a solution where active CMV was filtered out (FCMV). The total number (c) and total mass (d) of all breast tumors developed in MMTV-PyVT mice were quantified for 25 mice treated with a filtered control solution (FCMV) and for $23 \mathrm{mCMV}$-infected mice. The $p$-values were calculated by a one-way ANOVA (Figure 1a,b) or Student's $t$-test (Figure 1c,d) with $p<0.05$ considered to be significant. NS = not significant. 
We then studied MMTV-PyVT mice, which are on a C57BL/6 background, to provide a spontaneous model of breast cancer that better resembles the human situation. mCMV or FCMV was injected at 5 weeks of age to allow at least 10 weeks to develop a latent mCMV infection before the spontaneous tumors became palpable. The number of tumors per individual mouse was highly variable, as expected in this model, with a range from 1 to 10 tumors (Figure 1c). The total burden of tumor mass per mouse (Figure 1d) and the average volume, mass or density of tumors (Table 1) did not differ between the FCMV and mCMV groups at the experimental endpoint. The time required for mice to reach the experimental endpoint was also not significantly different [28].

Table 1. The average tumor volume, mass and density in MMTV-PyVT mice with and without a latent mCMV infection.

\begin{tabular}{ccccc}
\hline Variables & $\mathbf{n}$ & Mean $\pm \mathbf{S D}$ & $\mathbf{9 5 \%} \mathbf{C I}$ & $\boldsymbol{p}$-Value \\
\hline Tumor Volume $\left(\mathrm{mm}^{3}\right)$ & & & & \\
FCMV & 133 & $957 \pm 947$ & 795,1120 & 0.064 \\
CMV & 104 & $1202 \pm 1077$ & 993,1411 & \\
Tumor Mass $(\mathrm{mg})$ & & & & \\
FCMV & 133 & $0.84 \pm 0.85$ & $0.70,0.99$ & 0.164 \\
CMV & 104 & $1.01 \pm 0.96$ & $0.82,1.20$ & \\
Tumor Density & & & & \\
FCMV & 133 & $0.90 \pm 0.29$ & $0.85,0.95$ & 0.789 \\
CMV & 104 & $0.89 \pm 0.33$ & $0.82,0.95$ & \\
\hline
\end{tabular}

\subsection{Latent $m C M V$ Infection of MMTV-PyVT Mice Changed Breast Tumor Phenotype}

Each breast tumor in the MMTV-PyVT mice was examined for different phenotypes, which included the blood content categorized as pale, moderate or bloody tumors (Figure 2a); the tumor type characterized as single tumors, multilobed or fused small tumors (Figure 2b); and other morphologies (Table S1). Although an mCMV infection did not affect the number of tumors per mouse (Figure 1c), it did change the tumor phenotypes. On average, each mouse had one tumor that had a pale appearance. In the FCMV control mice, equal numbers of tumors per mouse were characterized as moderate or very bloody. By contrast, more tumors in each mCMV-infected mouse were very bloody (dark red) as opposed to containing a moderate amount of blood (pink) (Figure 2a). Very few or no tumors per mouse were characterized as a single tumor. The numbers of multilobed and fused small tumors in each FCMV control mouse were not significantly different. By contrast, a significantly greater proportion of fused small tumors were found in each mCMV-infected mouse compared to multilobed tumors (Figure 2b). When analyzing all tumors, we determined that tumors with more severe phenotypes such as high blood content $(p=0.005)$ or fused small tumors $(p=0.006)$ were more often found to be from the mCMV-infected mice. This was not the case with tumors that were solid, soft, necrotic, disintegrated or fluid-filled $(p=0.303)$ (Table S1). In addition, the odds ratio of having a fused small tumor combined with high blood content was 2.22 times higher (95\% CI 1.29, $3.84 ; p=0.004)$ in the mCMV-infected group compared to the FCMV controls [28]. 


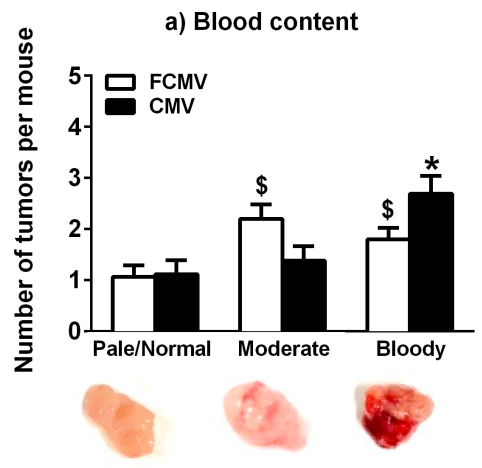

c) Breast tumors

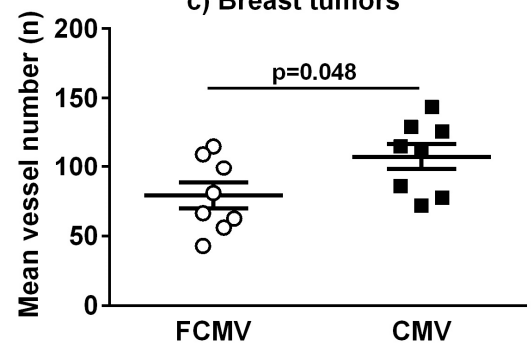

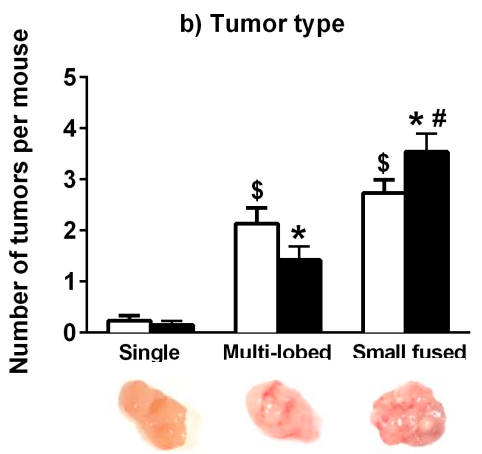

d)
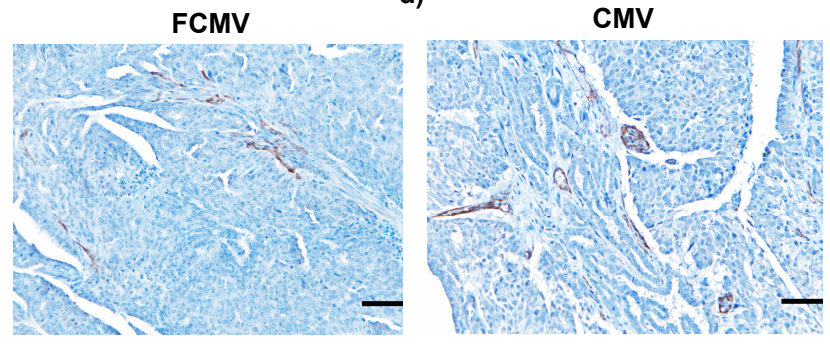

Figure 2. MMTV-PyVT mice latently infected with mCMV developed more breast tumors with severe phenotypes associated with metastasis. The tumors were categorized as pale/normal, moderate or bloody (a) or as a single tumor, multilobed or fused small tumors (b) in 25 control mice treated with a filtered control solution (FCMV) or in $23 \mathrm{mCMV}$-infected mice. The mean number and SEM for each type of tumor per mouse are shown, and the $p$-values were calculated by a two-way ANOVA and Tukey's post hoc test. A significant interaction between the treatment and phenotype was found in Figure $2 \mathrm{a}(p=0.009)$ and Figure $2 \mathrm{~b}(p=0.01) . \$=p<0.05$ compared to the pale/normal or single tumor in the FCMV group; ${ }^{*}=p<0.05$ compared to the pale/normal or single tumor in the mCMV group; $\#=p<0.05$ compared to multilobed in the CMV group. The number of blood vessels was assessed by the CD31 staining of sections of breast tumors from the mCMV-infected mice $(\mathbf{c}), \mathrm{n}=8$. The representative images of stained sections (d): The images were taken with a $20 \times$ magnification lens. Scale $=100 \mu \mathrm{m}$. The $p$-value was calculated using a Student's $t$-test.

The observed increase in the proportion of very bloody breast tumors in the mCMV-infected MMTV-PyVT mice was further investigated by assessing the number of blood vessels by staining for the endothelial marker, CD31. Eight mice from each group were chosen randomly, and the largest tumor at the endpoint from each mouse was used for analysis. These large tumors were bloodier with more fused lobes, regardless of treatment. The average number of blood vessels observed in the stained sections of the breast tumors from the mCMV-infected mice was significantly increased compared to those from the FCMV control mice (Figure 2c,d).

The amount of collagen was significantly lower in the breast tumors of mCMV-infected MMTV-PyVT mice compared to the controls (Figure 3). This could have reflected an increased collagen degradation, but there were no differences in the expression of MMP-2, MMP-3, MMP-8 (a collagenase), pro-MMP9 and MMP-12 in the tumors [28]. 

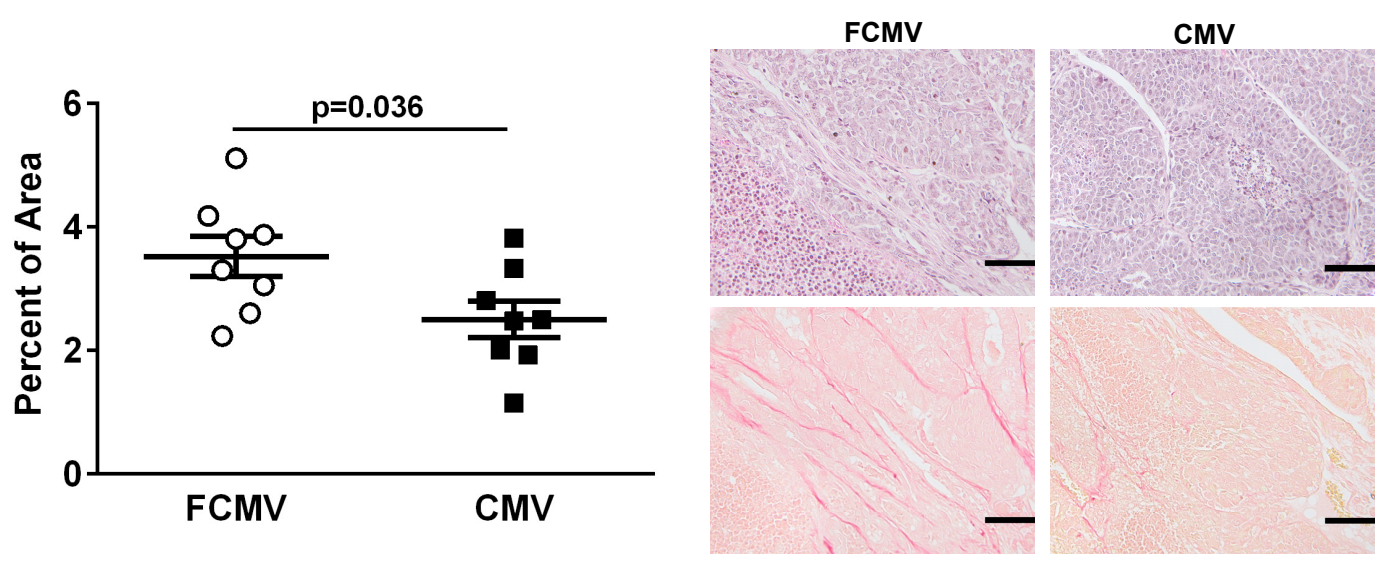

Figure 3. The tumors from MMTV-PyVT mice latently infected with mCMV had a lower collagen content. Collagen was quantified as the percent of total area in sections from the largest breast tumors from $\mathrm{n}=8$ mice in each group. Representative matched sections taken from the same area of the breast tumors were stained with hematoxylin and eosin for the detection of nuclei (top) and for collagen using picro-sirius red (bottom). The images were taken with a $20 \times$ magnification lens. Scale $=100 \mu \mathrm{m}$. The $p$-values were calculated by Student's $t$-test.

These combined results establish that, although the mCMV infection of MMTV-PyVT mice did not affect the tumor load, there was a difference in the tumor phenotype that could modify metastasis.

We also characterized the tumors from the C57BL/6 and BALB/c mice that were injected orthotopically with E0771 or 4T1 breast cancer cells, respectively. In these cases, there were no obvious differences in the tumor phenotypes in latently infected mice of either strain. The breast tumors from $\mathrm{BALB} / \mathrm{c}$ mice that were actively infected prior to the injection of breast cancer cells were also stained for CD31 and for collagen content. There were no significant differences between the UV-inactivated control and the mCMV-infected mice [28].

\subsection{Lung Metastasis Was Increased in mCMV-Infected BALB/c and MMTV-PyVT Mice}

Latently infected BALB/c mice showed a 3-fold increase in the number of metastatic nodules on the lung surface when compared to the PBS and UV-inactivated control groups (Figure 4a). However, this increase in lung metastasis was not observed in BALB/c mice with an active or intermediate mCMV infection prior to the introduction of the cancer cells (Figure S3e,f). The injection of E0771 cells into the mammary fat pads of C57BL/ 6 mice did not produce obvious macro- or micro-metastasis in the lungs or liver at the experimental endpoint for tumor growth [28].

Macro-metastatic nodules were not observed on lungs from the MMTV-PyVT mice, but sectioned lungs stained positively for micro-metastasis. The latent infection of MMTV-PyVT mice with mCMV resulted in 2-fold more lung nodules compared to the control mice. These nodules were also larger in the mCMV-infected group, and they occupied a 6-fold greater area of the lungs (Figure 4b-d). No significant micro-metastases were detected in the liver [28]. 
a) $B A L B / C$
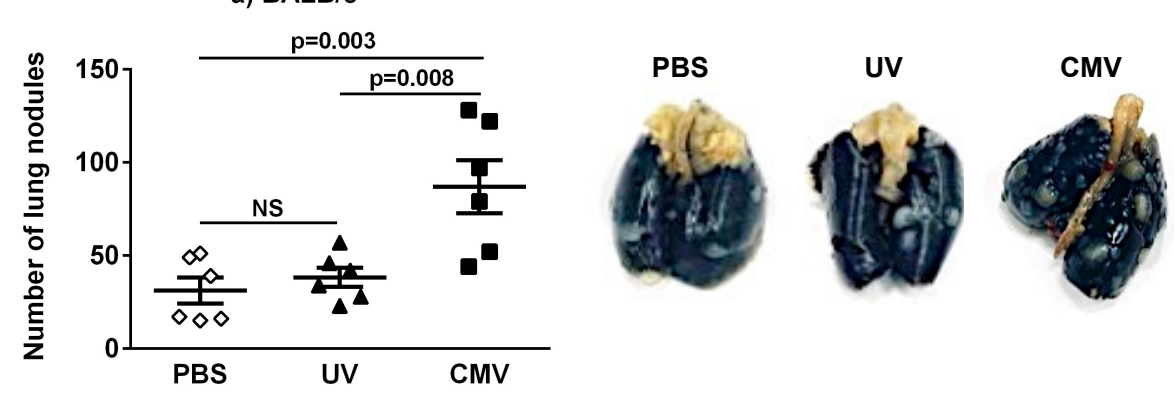

b) MMTV-PyVT
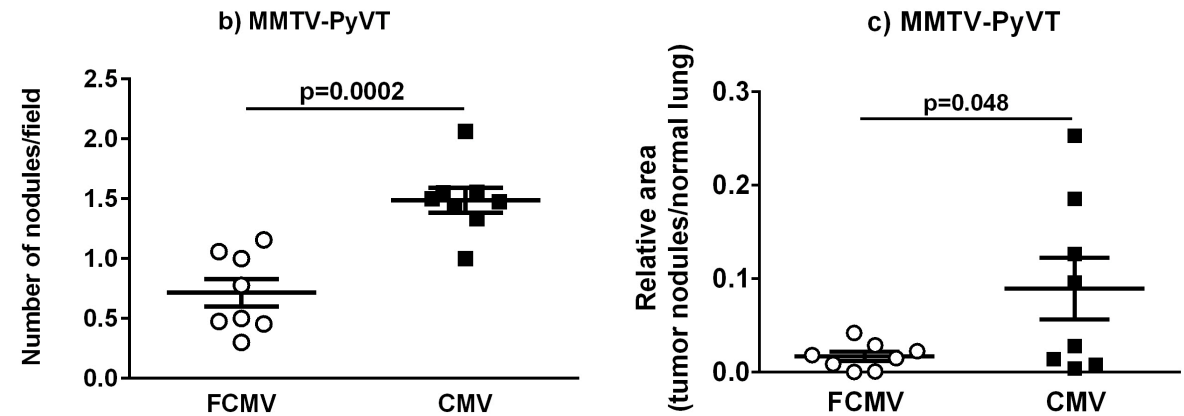

d) MMTV-PyVT

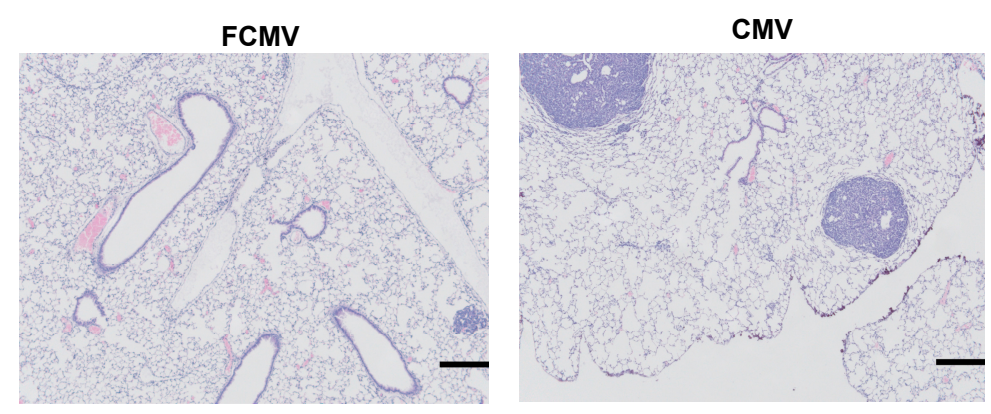

Figure 4. Lung metastasis was increased in mice latently infected with mCMV. The number of large lung nodules in the BALB/c model $(n=6)$ were quantified, and the representative lungs were depicted (a). Lung micro-metastasis in the MMTV-PyVT model $(\mathrm{n}=8)$ was assessed by staining with hematoxylin and eosin and analyzed as the number of nodules per microscopic field at $5 \times$ magnification $(\mathbf{b})$ and the area of nodules per lung area (c). The representative stained lung sections from the mice treated with a filtered control solution (FCMV) or mCMV with a $5 \times$ magnification lens are shown (d). Scale = 280 $\mu \mathrm{m}$. The $p$-values were calculated by a one-way ANOVA (Figure 4a) or Student's $t$-test (Figure $4 \mathrm{~b}, \mathrm{c}$ ). NS = not significant.

Cell proliferation was determined in the lung metastatic nodules and breast tumors for the MMTV-PyVT and BALB/c mice from the active and latent models by staining for Ki67. There was a 2-fold increase in the percentage of Ki67-positive cells in the metastatic nodules of MMTV-PyVT mice that were latently infected with mCMV compared to the FCMV control mice (Figure 5a,c). A significant increase in Ki67 positivity in lung nodules was also observed in the latently infected BALB/c mice compared to both the PBS and UV controls, but this difference was not observed in the actively infected model (Figure S4a,c). By contrast, there was no significant difference in the percentage of Ki67-positive cells in breast tumors between the controls and active or latently infected mice in all models tested (Figure 5b and Figure S4b,d). 

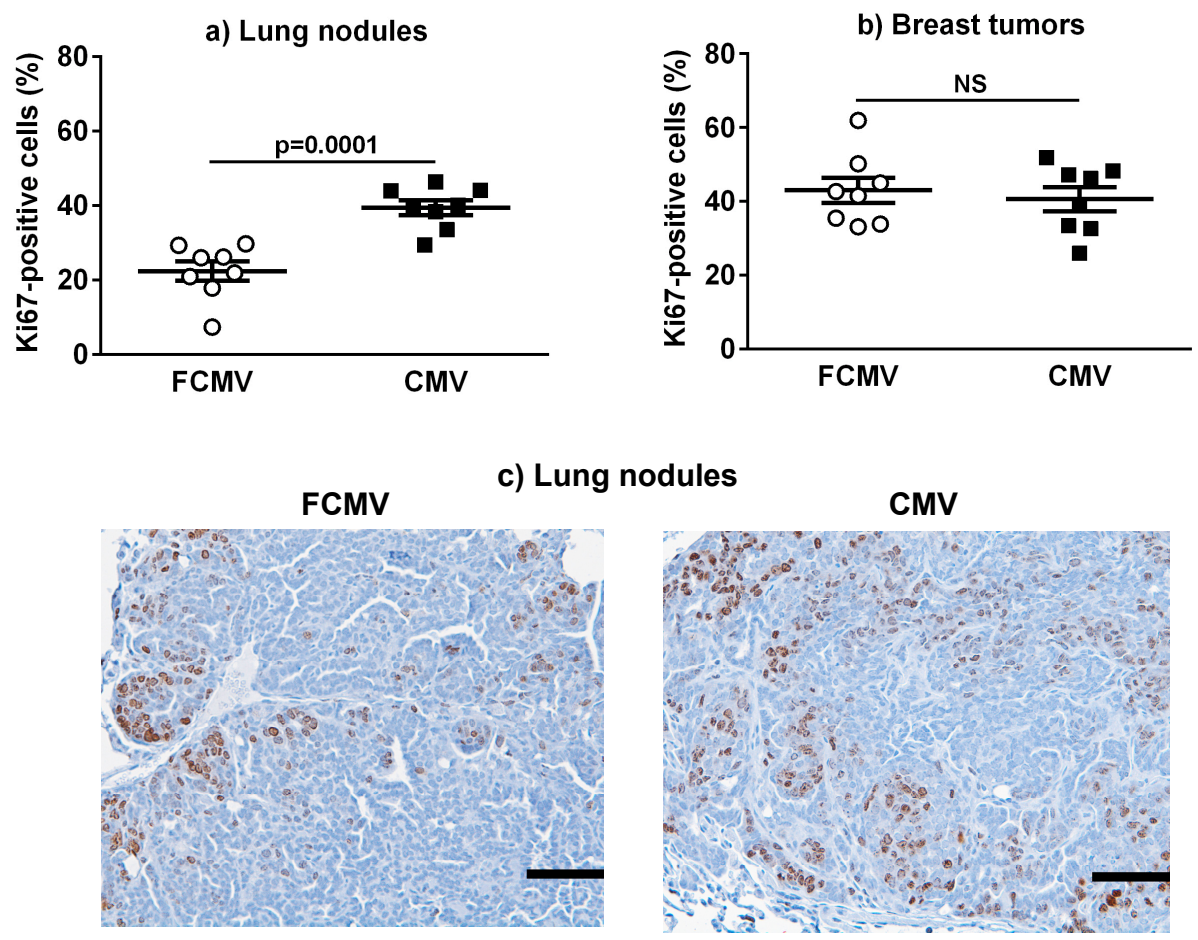

Figure 5. Cancer cell proliferation was enhanced in lung metastatic nodules but not in the breast tumors from MMTV-PyVT mice latently infected with mCMV. Lung metastatic nodules (a) and breast tumors (b) from mice treated with a filtered control (FCMV) or mCMV $(n=8)$ were stained for Ki67 to assess cell proliferation. The representative stained sections of lung nodules from FCMV- and mCMV-treated mice are illustrated (c). The image was taken with a $20 \times$ magnification lens. Scale $=100 \mu \mathrm{m}$. The $p$-values were calculated by Student's $t$-test. NS = not significant.

2.4. $m C M V$ DNA but Not mRNA Was Detectable in Tissues, Metastatic Nodules and Tumors from Mice Latently Infected with $m C M V$

We then tested for the presence of the viral genome by measuring mCMV gB DNA and for gene expression by measuring mRNA for $g B$, a viral gene which is transcribed at the late phase in viral replication. Salivary glands, spleens, lungs, lung metastatic nodules and breast tumors from mice latently infected with mCMV were examined. A sample was considered positive for viral gB DNA with the detection of a $235 \mathrm{bp}$ band after a nested PCR amplification of the gene with $\beta$-actin as the internal control. A representative gel of the breast tumor samples from MMTV-PyVT mice is shown in

The specific detection of viral gB DNA in the tissues, metastatic nodules or tumors tested for each mouse are delineated in Table S2. Apart from 2/6 animals in the C57BL/ 6 model and 1/23 in the MMTV-PyVT model, there was positive detection of DNA for $\mathrm{mCMV} \mathrm{gB} \mathrm{in} \mathrm{at} \mathrm{least} \mathrm{one} \mathrm{type} \mathrm{of} \mathrm{tissue,}$ nodule or tumor examined from each animal (Figure $6 b$ ). BALB/c mice had macro-nodules on the surface of the lungs that were separated from the underlying lung tissue. Half of these lung nodules from the BALB/c mice were positive for viral $\mathrm{gB}$ DNA compared to the $5 / 6$ positive underlying lung tissues. Macro-nodules were not present on the lungs of the C57BL/ 6 or MMTV-PyVT mice. Viral DNA for $\mathrm{gB}$ was detected in lung tissues from $83 \%$ of MMTV-PyVT mice but only $20 \%$ of the C57BL $/ 6$ mice. Viral DNA was detected in $50 \%$ and $26 \%$ of breast tumors from the MMTV-PyVT mice but none from the C57BL/ 6 mice. Similar results were obtained when detecting DNA for the mCMV IE- 1 gene in the MMTV-PyVT model [28]. The detection of viral DNA was not observed in any control mice, including PBS, UV-inactivated or FCMV-treated mice, which indicates that the mice were seronegative at the start of the experiments [28]. Figure 6a. 
a) Breast tumors in MMTV-PyVT

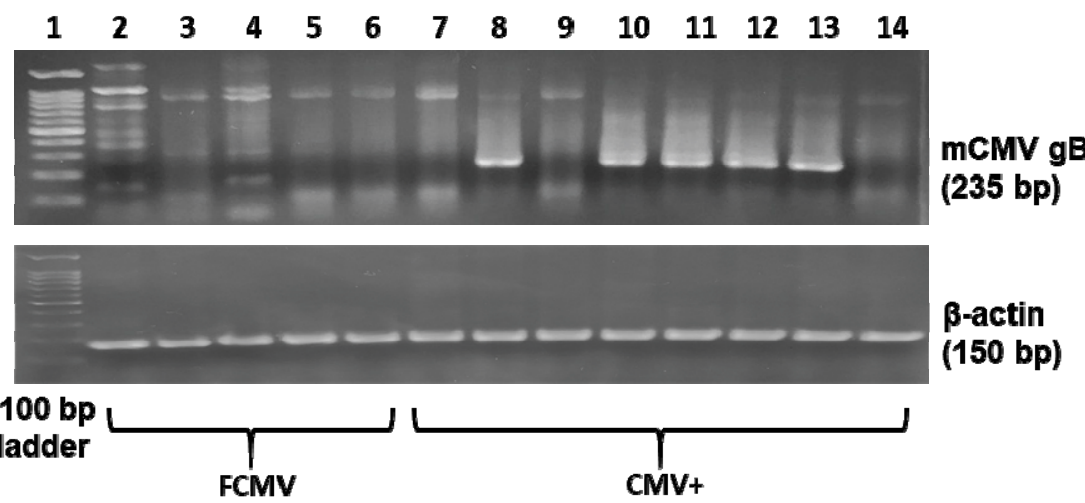

b) Summary table

\begin{tabular}{|c|c|c|c|c|c|c|}
\hline & \multicolumn{2}{|c|}{ BALB/c } & \multicolumn{2}{|c|}{ C57BL/6 } & \multicolumn{2}{|c|}{ MMTV-PyVT } \\
\hline & Positive/total & $\begin{array}{c}\% \\
\text { positive }\end{array}$ & Positive/total & $\begin{array}{c}\% \\
\text { positive }\end{array}$ & Positive/total & $\begin{array}{c}\% \\
\text { positive }\end{array}$ \\
\hline $\begin{array}{l}\text { Salivary } \\
\text { gland }\end{array}$ & $5 / 6$ & 83 & $2 / 5$ & 40 & $15 / 23$ & 65 \\
\hline Spleen & ND & ND & $3 / 5$ & 60 & $6 / 10$ & 60 \\
\hline Lung & $5 / 6$ & 83 & $1 / 5$ & 20 & $19 / 23$ & 83 \\
\hline $\begin{array}{c}\text { Lung } \\
\text { nodule }\end{array}$ & $3 / 6$ & 50 & NA & NA & NA & NA \\
\hline $\begin{array}{l}\text { Breast } \\
\text { tumor }\end{array}$ & $3 / 6$ & 50 & $0 / 5$ & 0 & $6 / 23$ & 26 \\
\hline
\end{tabular}

ND=Not done, NA=Not applicable

Figure 6. The DNA for mCMV glycoprotein B (gB) was detected in MMTV-PyVT mice latently infected with mCMV. The representative gel shows the detection of DNA for mCMV gB in breast tumors from five filtered control (FCMV; lanes 2-6) and eight mCMV-treated (lanes 7-14) MMTV-PyVT mice (a). Lane $1=100$ bp ladder. A positive detection of mCMV gB DNA was identified by a band at 235 base pairs (bp). Beta-actin (150 bp) was used as an internal control. The number of tissues, nodules or breast tumors positive for mCMV gB DNA from each animal model was summarized in Panel (b).

mCMV gB mRNA was also measured by RT-PCR to assess if there was an active infection. However, mRNA for $\mathrm{gB}$ was not detected in any tissues tested including salivary glands, spleens, lungs, metastatic nodules or tumors from the three mouse models [28]. Negative results were also obtained for mRNA detection of mCMV IE-1/3 [28]. In addition, tumors and lungs were stained for $\beta$-galactosidase activity, but no detection was observed in any of the experimental models [28]. Similar results were observed for the active infection models at the tumor endpoint [28].

\subsection{Cytokine Expression Was Altered in Breast Tumors and Plasma from Mice With Latent mCMV Infections}

We analyzed the plasma and tumors for 32 cytokines/chemokines using a Discovery 32-plex Array and only found the following significant differences: Breast tumors from MMTV-PyVT mice latently infected with mCMV had a decreased expression of interleukin-1-alpha (IL-1 $\alpha$ ) (Figure 7a). mCMV-infected mice had increased plasma concentrations of interleukin-6 (IL-6) and interleukin-13 (IL-13) compared to FCMV-treated mice (Figure 7b,c). There was a positive correlation between these concentrations of IL-6 and IL-13 for the mCMV-infected mice (Figure 7d; $p=0.0012$ ) but not for the FCMV-treated mice (Figure 7e; $p=0.34$ ). 

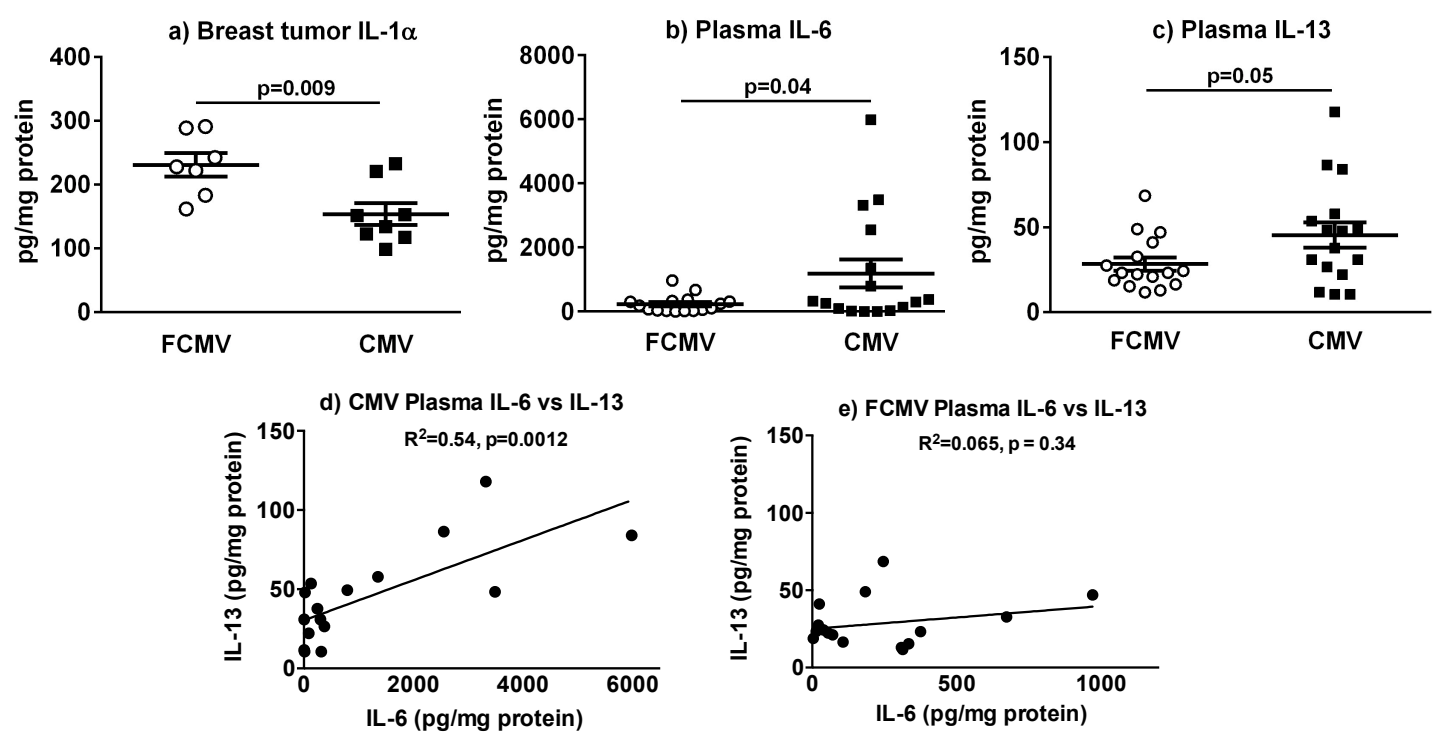

Figure 7. Cytokine concentrations differed in breast tumors and plasma from MMTV-PyVT mice latently infected with mCMV. Breast tumor levels of IL-1 $\alpha, n=8$ (a). Plasma concentrations of IL-6 (b) and IL-13 (c), $\mathrm{n}=16$. The regression analysis of plasma concentrations IL-6 versus IL-13 in mCMV-infected (d) and mice treated with a filtered control solution (FCMV) (e). The $p$-values were calculated by Student's t-test.

\section{Discussion}

The association between HCMV and breast cancer has been studied over the past two decades, but the role of HCMV still remains controversial [29]. Very little is known about the mechanisms by which CMV infection could modify tumor progression. We investigated the effects of mCMV infection on breast cancer progression using three mouse models of breast cancer and showed, for the first time, that latent $\mathrm{mCMV}$ infections prior to tumor development increase metastasis to the lungs.

We detected viral DNA in the latently infected mice at least once when we analyzed the metastatic nodules, breast tumors or various tissues including salivary gland, spleen or lungs. We determined if the presence of a breast tumor or metastasis initiated mCMV reactivation. This state of a latent CMV infection resembles that commonly found in immunocompetent people [6]. CMV latency is established in hematopoietic progenitor cells and in cells of the myeloid/monocyte lineage that serve as a reservoir for the viral genome [30,31]. The reactivation of CMV occurs in differentiated myeloid macrophages and dendritic cells [32-34]. These immune cells infiltrate the tumor site, and they are important components of the tumor microenvironment [35]. The role of these immune cells in our animal models is unknown. The presence of DNA but the lack of detection of mRNA for $\mathrm{mCMV} \mathrm{gB}$, IE- $1 / 3$ and $\beta$-galactosidase activity in tissues, nodules and tumors confirmed latency. This surprised us since we had predicted that tumor-induced inflammation would cause viral reactivation. These results suggest that the full active replication of the virus was not required for the observed increase in lung metastasis. Furthermore, mice actively infected with mCMV prior to tumor development also showed no positive detection of $\beta$-galactosidase activity in the tumors, and this indicates that breast cancer cell inoculation and tumor growth did not maintain mCMV infection at an active status. However, the immune response to the active infection at the time the tumor is developing could establish a microenvironment that reduces the metastatic phenotype, conferring some protection similar to heterologous immunity where infection with one pathogen can protect against another $[12,13]$. However, mRNA and $\beta$-galactosidase analyses were only performed at the experimental endpoint and in a limited number of tissues. It is possible that viral reactivation could have occurred once or multiple times prior to the endpoint and/or in other tissues where reactivation would have been quickly controlled by an intact memory immune response. Short phases of viral reactivation would have an impact on the immune responses that could play a role in metastasis. This explanation is 
likely since there is evidence of an active HCMV infection with HCMV proteins found in the metastatic sentinel lymph nodules of breast cancer patients [24]. Alternatively, proteins produced at a low level from latency associated transcripts, which include IE- 1 in the absence of the transactivator IE-3 [36], or a splice variant of cmvIL-10 could also play a role in metastasis by controlling the immune response. It is also possible that the level of transcription for CMV mRNA was below the limit of detection with our current technique.

The effects of an mCMV infection on breast tumor progression were studied in BALB/c mice and C57BL/ 6 mice where we orthotopically injected syngeneic $4 \mathrm{~T} 1$ or E0771 breast cancer cells, respectively, into mammary fat pads. C57BL/ 6 mice are less affected by infection with mCMV because of an effective natural killer cell response [37]. By contrast, BALB/c mice are more negatively affected by infection with mCMV because they lack the natural killer cell Ly49H activating receptor that recognizes an MHC class I-like glycoprotein produced during an mCMV infection [37]. This leads to an initial inefficient clearance of mCMV that impacts viral load and helps explain why we detected mCMV DNA more frequently in BALB/c than C57Bl/6 mice. Despite this greater sensitivity of BALB/c mice to $\mathrm{mCMV}$ infection, we only found an effect on metastasis in latently infected mice. The absence of an increased metastases in the mice acutely infected prior to tumor growth could have resulted from a more robust immune response to the virus when the syngeneic cancer cells were injected. If so, this only affected metastasis and not tumor growth.

We also examined the effect of a latent mCMV infection in a mouse model with the spontaneous growth of multiple breast tumors. MMTV-PyVT mice express the polyomavirus middle T (PyVT) oncogene under the direction of the mouse mammary tumor virus (MMTV) promoter/enhancer [38]. These mice provided a very relevant model for human breast cancer since they could be infected early in life and the effects of the mCMV infection on the development of spontaneous breast tumors and metastasis could be determined.

We evaluated the effects of active, intermediate and latent infections with $\mathrm{mCMV}$ on breast tumor growth and metastasis in BALB/c and C57BL/ 6 models. The results in the BALB/c model were consistent in that there was mostly no significant effect of the mCMV infection regardless of timing on breast tumor volume or mass when compared to the control treatments. The significantly higher tumor mass in latently infected BALB/c mice compared to control mice treated with PBS is probably not important since there was no significant difference between the infected mice and those treated with a UV-inactivated virus (Figure 1A). Treatment with a UV-inactivated virus involved the injection of intact virus particles, which cannot replicate but can be recognized by the host immune system, providing a highly relevant control. In the C57BL/ 6 model, while there was no effect of intermediate or latent infection on tumor volume or mass, $\mathrm{mCMV}$ infection reduced tumor volume but not mass during an active infection. This is likely because the tumors in this model were less solid, reducing the accuracy of measurement with calipers.

The BALB/c model was established with an injection of $4 \mathrm{~T} 1$ breast cancer cells, mimicking stage IV human breast cancer that form macro-metastases in the lungs [39]. The C57BL/6 model [40] and the MMTV-PyVT mice [41] develop much smaller metastases in the lungs and liver at a late stage of breast tumor development. As expected, our study in the C57BL/ 6 model showed no metastases in lungs and liver because of the ethical requirements to terminate our experiments at an earlier endpoint because of tumor size. The BALB/c and the MMTV-PyVT mice showed metastases in the lungs, which were increased significantly when the mice were latently infected with $\mathrm{mCMV}$ prior to tumor development. The increased metastases observed with a latent mCMV infection were not observed in the active or intermediate mCMV infection models. This work provides evidence from a mouse model that supports the contribution of HCMV infection to breast cancer metastasis and adds to the finding of a high rate of detection of HCMV proteins in the metastatic sentinel lymph nodules of breast cancer patients [24]. The establishment of these relevant preclinical models will also allow in-depth investigations into mechanisms. 
The results from the MMTV-PyVT mice confirmed that a latent mCMV infection had no significant effects on breast tumor growth and final tumor mass, but it did lead to worse phenotypes with the potential to promote metastasis. Multiple breast tumors developed in each MMTV-PyVT mouse, and we used the largest tumor for the endpoint measurements since these had almost identical sizes. There was a greater incidence of small fused breast tumors that were bloodier in the mCMV-infected mice, which could be indicative of a more severe phenotype. The breast tumors from mCMV-infected mice also had increased numbers of blood vessels, which is compatible with the overall increased bloodiness. Together, these results showed that a latent mCMV infection of MMTV-PyVT mice increased angiogenesis in breast tumors. This is a known feature associated with CMV infection [42,43], and it is important for metastasis [44]. Also, there were lower collagen levels in breast tumors from mCMV-infected mice, which is compatible with increased cancer cell egress [45]. In contrast, breast tumors from the actively or latently infected mCMV BALB/c model did not show these phenotype changes, including microvasculature and collagen content. This was possibly due to the differences between the type of breast tumor developed by using $4 \mathrm{~T} 1$ cells, which results in a relatively solid tumor with a low blood content.

Cell proliferation, as measured by Ki67, was not significantly different in the breast tumors between the mCMV-infected and control-treated MMTV-PyVT or BALB/c mice. This result was compatible with our finding that the average size of the tumors was not significantly different. This was despite the greater vascularization of the breast tumors from MMTV-PyVT mice that presumably increased $\mathrm{O}_{2}$ and nutrient supply. By contrast, there was a greater cell proliferation in the lung micro-metastatic nodules of the infected MMTV-PyVT mice, which corresponds to the larger size of the nodules. The increased cell proliferation of lung nodules was only observed in the latently but not in the actively infected BALB/c model. These results were compatible with the increased numbers of macro-metastatic nodules that were seen only in the latently infected mice. The explanation for the specific effects of latent CMV infection prior to tumor growth in increasing metastasis could be in the specific expression of latency expressed viral proteins, and this will be the subject of future investigations.

The FCMV control would have included cytokines and growth factors produced by the CMV-infected fibroblasts during CMV propagation. This control could also have contained small $\mathrm{CMV}$ viral fragments and small particles such as exosomes that were not removed by filtration. More importantly, the UV-inactivated control contained intact viral particles that were no longer infective. Both controls have the potential to stimulate a host immune response, which could have altered the tumor progression. However, similar effects were observed irrespective of using FCMV, UV inactivation or PBS controls.

The mechanisms for increased metastasis in mCMV-infected mice are probably complex, involving changes in the capacity of breast cancer cells to migrate from the primary tumor and to increase their ability to travel, establish and divide in distant sites. Along with changes in the tumor morphology that promote metastasis, mCMV-induced changes could also modify the host immune response so that cancer cells escape from immune destruction and aggravate tumor-promoting inflammation that favors tumor metastasis [46]. Our observation of the decreased IL- $1 \alpha$ expression in the breast tumors of mCMV-infected MMTV-PyVT mice suggests that mCMV plays a role in immune regulation and affects the inflammatory condition at the breast tumor site. IL- $1 \alpha$ also stimulates collagen synthesis $[47,48]$, and lower concentrations of IL- $1 \alpha$ in the tumors are compatible with the decreased collagen content. We also checked for evidence of an increased collagen breakdown, but there were no significant differences in the concentrations of the collagenase, MMP-8, in the tumors or for other MMPs (MMP-2 MMP-3, pro-MMP9 and MMPP-12) that could favor metastasis.

Plasma concentrations of the pro-inflammatory cytokine, IL-6, were increased in mCMV-infected mice. This is a common feature associated with CMV infection [49] and is reported to have a role for carcinogenesis in salivary gland cancer [50]. An increase was also observed for IL-13, which promotes cell migration and invasion in colorectal cancer [51]. We observed a significant positive correlation 
between IL-6 and IL-13 in CMV-infected mice, and the significance of these changes are areas for future investigations. However, the present results provide important insights into potential mechanisms for HCMV infection and human breast cancer and metastasis.

This study provides the first direct evidence from three mouse models of breast cancer that mCMV infection increases metastasis but does not affect the growth of primary tumors. This is compatible with the general conclusion that CMV is a tumor modulatory virus and not tumorigenic. Thus, the major finding was that a latent but not active $\mathrm{mCMV}$ infection prior to tumor development increases metastasis both in terms of the number of lung nodules and their size. This indicates that latent HCMV infections could play a crucial role in increasing mortality in breast cancer patients. Significantly, HCMV infects $40-70 \%$ of the adult population, but these numbers are reported to be as high as $95 \%$ in women with breast cancer. Little attention is given to the effects that HCMV infection could have on the current treatments of breast cancer. Our results provide evidence from mouse breast cancer models that latent mCMV infections prior to tumor development increase metastasis to the lungs. This work raises the possibility that treating the effects of HCMV infections or, alternatively, preventing HCMV infection altogether could substantially decrease metastasis and increase the life expectancy of breast cancer patients.

\section{Materials and Methods}

\subsection{Mouse Breast Cancer Models and Genotyping}

Female BALB/c and C57BL/6 mice at 8 to 10 weeks of age were purchased from Charles River (Kingston, ON, Canada). Syngeneic orthotopic mouse breast cancer models were established as described [52], with the injection of 20,000 mouse 4T1 breast cancer cells (American Type Culture Collection, Manassas, VA, USA) in BALB/c mice and $10^{6}$ mouse E0771 breast cancer cells (CH3 BioSystems, Amherst, NY, USA) in C57BL/6 mice. A spontaneous mouse breast cancer model was generated by breeding male mice that were hemizygous for B6.FVB-Tg (MMTV-PyVT)634Mul/LellJ [38] with wild type female C57BL/6 mice. Ear notch samples were collected from weaned female mice, and the DNA was extracted using a DNeasy Blood \& Tissue Kit (Qiagen, Toronto, ON, Canada). PCR was performed using the following program: initial denaturation for $30 \mathrm{sec}$ at $98^{\circ} \mathrm{C}, 35$ cycles of denaturation for $10 \mathrm{sec}$ at $98^{\circ} \mathrm{C}$, annealing for $20 \mathrm{sec}$ at $64^{\circ} \mathrm{C}$, elongation for $25 \mathrm{sec}$ at $72{ }^{\circ} \mathrm{C}$ and then a final elongation for $5 \mathrm{~min}$ at $72{ }^{\circ} \mathrm{C}$. The reaction mixture contained $1 \mu \mathrm{L}$ of DNA extract in a $25 \mu \mathrm{L}$ reaction volume containing $2 \times$ PCR Taq Master Mix (Applied Biological Materials, Richmond, BC, Canada). Two sets of primers were added simultaneously to the reaction. Internal control: sense $5^{\prime}$-CAA ATG TTG CTT GTC TGG TG-3' and antisense $5^{\prime}$-GTC AGT CGA GTG CAC AGT TT-3' (gives 200 bp product). PyVT: sense 5'-GGA AGC AAG TAC TTC ACA AGG G-3' and antisense $5^{\prime}$-GGA AAG TCA CTA GGA GCA GGG-3' (gives 556 bp product). The primers were purchased from Integrated DNA Technologies (Coralville, IA, USA). The products were visualized after electrophoresis on a $2.0 \%$ agarose gel that was stained with ethidium bromide. Female mice that were positive for both the internal control and PyVT were used for the experiments.

The mice were housed in Animal Biosafety Level 2 containment in the Health Sciences Laboratory Animal Services facility at the University of Alberta. All procedures were approved by the University of Alberta Animal Welfare Committee and followed guidelines from the Canadian Council of Animal Care.

\subsection{Preparation of $m C M V$}

RM427+, a strain of mCMV containing an insertion of the LacZ gene in the nonessential immediate-early 2 gene, was used for infection (gift from E. Mocarski, Stanford University, Stanford, CA, USA) [27]. The infection with RM427+ did not differ from the native virus strain [27]. The virus was propagated in mouse fibroblasts and stored as aliquoted viral stocks at $-80{ }^{\circ} \mathrm{C}$ as previously described [27]. A filtered control (FCMV) was generated by passing the propagated $\mathrm{mCMV}$ through 
a $0.05 \mu \mathrm{m}$ membrane filter (Millipore Sigma, Tullagreen, Carrigtwohill Co. Cork, IRL) to eliminate the viral particles but to retain the propagation medium. A UV-inactivated control was generated by irradiating the propagated $\mathrm{mCMV}$ with a 230-volt UV lamp from $20 \mathrm{~cm}$ for $30 \mathrm{~min}$. Both control solutions showed no viral infection when cultured with mouse fibroblasts.

\subsection{Mouse Infection with $m C M V$}

mCMV $\left(10^{6}\right.$ plaque-forming units, $\left.\mathrm{PFU}\right)$ was injected i.p. in $100 \mu \mathrm{L}$ [27] in mice chosen at random. An equal volume of phosphate-buffered saline (PBS), FCMV or the UV-inactivated virus was injected as a control into the other mice.

Each strain of mouse was tested for a successful active infection using separate test animals injected with the controls described above or mCMV. The mice were then euthanized after 4 days, and the kidneys were harvested, embedded in an optimal cutting temperature compound (Fisher Scientific International Inc., Ottawa, ON, Canada) and stored at $-80^{\circ} \mathrm{C}$. The LacZ gene inserted into the IE-2 gene of $\mathrm{mCMV}$ produced $\beta$-galactosidase when the virus was actively replicating, and this was visualized by its activity in converting $X$-gal into a blue product. The kidneys were sectioned and stained for $\beta$-galactosidase activity using the LacZ Detection Kit for Tissues (InvivoGen, San Diego, CA, USA) following the manufacturer's instructions. Latency was defined as the presence of mCMV genome but the absence of mRNA for $\mathrm{gB}$, a transcript produced in the late phase of infection but not produced in latency [53].

The infection of BALB/c and C57BL/ 6 mice was for 4 days, 11 days or 10 weeks to generate an active, intermediate or latent infection, respectively, before injecting E0771 or 4T1 breast cancer cells, respectively into a mammary fat pad [52]. The MMTV-PyVT mice were infected at 5 weeks of age, allowing at least 10 weeks for a latent infection to develop before spontaneous breast tumors were first palpable.

\subsection{Tumor Growth and Tissue Collection}

Tumor growth was monitored by taking orthogonal caliper measurements in two dimensions and estimating the tumor volume by width ${ }^{2} \times$ length $/ 2$. The syngeneic-orthotopic models had a single tumor develop per mouse, and the experimental endpoint was 25 days post-cancer cell inoculation so the estimated tumor volume was approximately $1000 \mathrm{~mm}^{3}$. The MMTV-PyVT mice developed multiple spontaneous tumors with a high intrinsic variability, and the experimental endpoint was when the largest tumor reached $4000 \mathrm{~mm}^{3}$. Salivary glands and spleens were immediately snap frozen in liquid nitrogen and stored at $-80^{\circ} \mathrm{C}$. The tumors were isolated and weighed, and their morphological characteristics assessed by two independent observers who were blinded to the treatment group. The amount of blood in the tumor was categorized as pale, moderate or bloody, with the tumors being pale, pink or dark red in color, respectively. The number of lobes on the tumor was categorized as single tumor, multilobed (lobes started to form on the original tumor) or fused small tumors (fusion of largely grown lobes). Further characterization of each tumor was made with respect to morphology including whether they were solid, soft, necrotic, disintegrated or fluid-filled. Half of each tumor was snap frozen, and the other half was fixed in $10 \%$ formalin.

\subsection{Metastasis}

The lungs from BALB/c mice were stained with India ink (American MasterTech, Lodi, CA, USA) by intratracheal injection, leaving the metastatic nodules as white against the black lung [54]. The total number of nodules observed on the lung surface was counted. The nodules were then carefully isolated from the lung tissue under a dissection microscope for analysis to detect mCMV. The livers and lungs from C57BL/ 6 and MMTV-PyVT mice were fixed with 10\% formalin. Lung micro-metastasis was determined using fixed lung specimens that were paraffin-embedded. Sample slices were obtained from the front, middle and back sections of the lung and stained with hematoxylin and eosin to identify tumor nodules. Briefly, hydrated slides were stained with hematoxylin for $3 \mathrm{~min}$, rinsed 
with running tap water for $5 \mathrm{~min}$, differentiated with $0.3 \%$ concentrated hydrochloric acid in $80 \%$ ethanol, stained with eosin for $45 \mathrm{~s}$ and dehydrated. The images were taken from 5 fields per section with a $5 \times$ magnification lens, and staining was quantified by ImageJ (National Institutes of Health, Bethesda, MD, USA) for the number of nodules per microscopic field and area of nodules relative to the corresponding lung area. Liver micro-metastasis was examined using the same technique.

\subsection{Immunohistochemistry}

Breast tumors and lungs fixed in 10\% formalin were embedded in paraffin and sectioned. The hydrated slides were microwaved in a Tender Cooker (Nordic Ware, Minneapolis, MN, USA) for $30 \mathrm{~min}$ in $10 \mathrm{mM}$ citric acid ( $\mathrm{pH}$ 6.0) for antigen retrieval. A Rabbit-specific HRP/DAB (ABC) Detection IHC Kit (Abcam, Toronto, ON, Canada) was used according to the manufacturer's instructions. The rabbit anti-CD31 (ab28364, 1:80) antibody was from Abcam (Toronto, ON, Canada), and the rabbit anti-Ki67 (D3B5, 1:200) was from Cell Signaling Technology (Whitby, ON, Canada). Positive staining events for CD31 and Ki67 were selected and counted using ImageJ. An analysis was made using images taken with a $5 \times$ magnification lens, and the illustration was taken with a $20 \times$ magnification lens. CD31 was quantified as the number of vessels per field, and Ki67 as a percentage of the positive cells. The results were averaged from 10 image fields for each sample.

\subsection{Picro-Sirius Red Staining for Collagen}

Sectioned breast tumor slides were hydrated and incubated for $1 \mathrm{~h}$ with $0.1 \%$ Sirius Red F3B (Sigma-Aldrich, Oakville, ON, Canada) dissolved in a saturated aqueous solution of picric acid, washed twice with $0.5 \%$ acetic acid and then dehydrated [55]. Collagen type I, III and IV were stained red against a pale orange background when visualized under light microscope. Areas of positive staining were quantified using Adobe Photoshop (Adobe Inc., San Jose, CA, USA) and Image J software. The results were averaged from 10 image fields for each sample.

\section{8. $m C M V$ Viral DNA Detection}

The tissues were isolated for DNA analysis using the DNeasy Blood \& Tissue Kit (Qiagen, Toronto, $\mathrm{ON}$, Canada). The presence of mCMV DNA was detected using primer sets from Integrated DNA Technologies (Coralville, IA, USA) that were specific for the late gene mCMV gB [56]. The mCMV gB external primers were sense $5^{\prime}$-TCA TCA ACT CGA CGA AGC TC- $3^{\prime}$ and antisense $5^{\prime}$-ATC TCG TCC AGG CTG AAC AC-3' (giving a 298-bp product), and the mCMV gB internal primers were sense 5'-CTG GGC GAG AAC AAC GAG AT-3' and antisense 5'-CGC AGC TCT CCC TTC GAG TA-3' (giving a 235-bp product). The detection of mCMV DNA from the IE-1 region was also performed, the external primers were sense $5^{\prime}$-TGG ATG AGA ACC GTG TCT AC- $3^{\prime}$ and antisense $5^{\prime}$-ATA TCA TCT TGC GTT GTC TT-3' (giving a 549-bp product) and the internal primers were sense $5^{\prime}$-TAC AGG ACA ACA GAA CGC TC- $3^{\prime}$ and antisense $5^{\prime}$-CCT CGA GTC TGG AAC CGA AA-3' (giving a 310-bp product) [57]. Nested PCR was performed for both sets of primers using the $2 \times$ PCR Taq Master Mix (Applied Biological Materials, Richmond, BC, Canada) in a $25 \mu \mathrm{L}$ reaction volume. The extracted DNA (300 ng) was amplified with the external primer set for the first round of amplification and then $2 \mu \mathrm{L}$ of the amplified product was used with the internal primer set for the second round of amplification. Both rounds of PCR were performed with the following program: initial denaturation for $4 \mathrm{~min}$ at $94{ }^{\circ} \mathrm{C}, 35$ cycles of denaturation for $30 \mathrm{sec}$ at $94{ }^{\circ} \mathrm{C}$, annealing for $30 \mathrm{sec}$ at $53{ }^{\circ} \mathrm{C}$ for gB and $60{ }^{\circ} \mathrm{C}$ for IE-1, elongation for $30 \mathrm{sec}$ at $72{ }^{\circ} \mathrm{C}$ and then a final elongation for $7 \mathrm{~min}$ at $72{ }^{\circ} \mathrm{C}$. The internal control used was $\beta$-actin (gives 150-bp product): sense $5^{\prime}$-ATT GTG ATG GAC TCC GGT GA-3' and antisense $5^{\prime}$-AGC TCA TAG CTC TTC TCC AG-3' . The products were detected after electrophoresis on a $1.5 \%$ agarose gel that was stained with ethidium bromide. 


\section{9. $m C M V$ mRNA Detection}

The tissues were homogenized in $1 \mathrm{~mL}$ of Trizol (Invitrogen Life Technologies, Grand Island, NY, USA) contained in $2 \mathrm{~mL}$ microcentrifuge tubes with 5-mm stainless steel beads, using the Qiagen TissueLyser II system (24-sample plates, $25 \mathrm{~Hz}, 5 \mathrm{~min}$ ) (Qiagen, Toronto, ON, Canada). The RNA was isolated using the ultRNA Column Purification kit (Applied Biological Materials, Richmond, BC, Canada). cDNA was produced by PCR using Reverse Transcription master mix, and the relative amount of the target gene was quantified by Real-Time PCR using EvaGreen qPCR master mix (Applied Biological Materials, Richmond, BC, Canada). The relative abundance of mCMV gB expression at the mRNA level was determined by normalizing against the housekeeping gene, glyceraldehyde 3-phosphate dehydrogenase (GAPDH). mCMV gB (primer for mRNA): sense 5'-AGG GCT TGG AGA GGA CCT ACA-3' and antisense $5^{\prime}$-GCC CGT CGG CAG TCT AGT C-3'. mCMV IE-1/3: sense $5^{\prime}$-GTA CAA AAG GTC AAT AGG GG-3' and antisense $5^{\prime}$-GTA CCG ACG CTG GTC GCG CC-3'. GAPDH: sense $5^{\prime}$-TCC TGC ACC ACC AAC TGC TT- $3^{\prime}$ and antisense $5^{\prime}$-TCT TAC TCC TTG GAG GCC AT- $3^{\prime}$.

\subsection{Cytokine/Chemokine and Matrix Metalloproteinase (MMP) Expressions}

The breast tumors $(20 \mathrm{mg}$ ) were homogenized in $200 \mu \mathrm{L}$ of radioimmunoprecipitation buffer (50 mM Tris- $\mathrm{HCl}$ (pH 7.4), 1\% NP-40, 0.25\% Na-deoxycholate, $150 \mathrm{mM} \mathrm{NaCl}, 1 \mathrm{mM}$ EDTA, 1:100 dilution of protease inhibitor) and centrifuged for $20 \mathrm{~min}$ at $4{ }^{\circ} \mathrm{C}$. The supernatants were then transferred to a fresh tube. Protein concentration was measured using the bicinchoninic acid protein assay (Thermo Fisher Scientific, Rockford, IL, USA) and adjusted to $1 \mathrm{mg} / \mathrm{mL}$. This protein solution and plasma samples were analyzed using a Mouse Cytokine/Chemokine Discovery array 32-plex and for MMP expression by Eve Technologies Corp (Calgary, AB, Canada).

\subsection{Statistics}

Results other than tumor characteristics in the MMTV-PyVT model are expressed as means \pm SEM. Student's t-test, one-way ANOVA or two-way ANOVA were used as appropriate and indicated in each figure legend. $p<0.05$ was considered significant as evaluated and graphed using GraphPad Prism 6 (GraphPad Software, La Jolla, CA, USA). Changes in the number of tumors by blood content, type of tumors and morphology (severity characteristics) across infection status (with/without mCMV infection) were estimated by a Chi-square analysis (and Fisher's exact test when applicable). An additional logistic model was used to assess the odds ratio of severity characteristics between the with/without mCMV infection groups as suggested by the results of the Chi-square analysis. The Chi-square analysis and the logistic models were performed using SPSS version 25.0 [58] and $p$-values of $<0.05$ were considered to be statistically significant.

\section{Conclusions}

This study provides the first direct evidence from mouse breast cancer models that latent mCMV infections prior to tumor development increase metastasis to the lungs but do not affect tumor growth. This work raises the possibility that treating the effects of HCMV infections or, alternatively, preventing HCMV infection altogether could substantially decrease metastasis and increase the life expectancy of breast cancer patients.

Supplementary Materials: The following are available online at http:/ / www.mdpi.com/2072-6694/11/4/447/s1, Table S1: Severity of tumors in MMTV-PyVT mice with and without latent mCMV infection, Figure S1: Verification of successful mCMV infection, Figure S2: Estimated volume of breast tumors developed over time in BALB/c and C57BL/ 6 mice with and without active, intermediate or latent mCMV infections, Figure S3: Breast tumor mass and lung metastasis were not significantly affected in mice with active or intermediate mCMV infections, Figure S4: Evidence of enhanced cancer cell proliferation in lung metastatic nodules of BALB/c mice latently infected prior to cancer cell injection, but not in the mice actively infected prior to cancer cell injection, Table S2: Detection of mCMV glycoprotein B DNA in specific tissues, nodules or tumors from each mouse in all animal groups. 
Author Contributions: D.N.B. and D.G.H. conceived and designed the experiments; Z.Y., X.T., G.M., M.G.K.B. and M.M. performed various aspects of the experiments. I.S.G. provided the breeding pairs of MMTV-PyVT mice and helped to design the experimental endpoints with these animals. A.P.B. and J.S.-L. performed the statistical analysis of the tumor phenotypes. Z.Y. drafted the manuscript with D.N.B. and D.G.H., and all authors revised and approved the final version of the manuscript.

Funding: The work was supported by Grants from the Canadian Cancer Society Research Institute, the Canadian Breast Cancer Foundation (CBCF) and the Women and Children's Health Research Institute at the University of Alberta. Z. Yang received a 75th Anniversary Graduate Studentship, a Dean's Doctoral Award from the Faculty of Medicine and Dentistry at the University of Alberta and a studentship award from La Vie en Rose through the Cancer Research Institute of Northern Alberta.

Acknowledgments: We thank Ms. Raven Kirschenman for help with the breeding and management of the MMTV-PyVT mice.

Conflicts of Interest: There are no conflicts of interest.

\section{Abbreviations}

$\begin{array}{ll}\text { CMV } & \text { cytomegalovirus } \\ \text { FCMV } & \text { filtered cytomegalovirus } \\ \text { GAPDH } & \text { glyceraldehyde 3-phosphate dehydrogenase } \\ \text { gB } & \text { glycoprotein B } \\ \text { HCMV } & \text { human cytomegalovirus } \\ \text { IE } & \text { immediate early } \\ \text { IL } & \text { interleukin } \\ \text { mCMV } & \text { mouse cytomegalovirus } \\ \text { MMP } & \text { matrix metalloproteinase } \\ \text { MMTV } & \text { mouse mammary tumor virus } \\ \text { PyVT } & \text { polyomavirus middle T }\end{array}$

\section{References}

1. American Cancer Society. Breast Cancer Facts \& Figures 2017-2018; American Cancer Society Inc.: Atlanta, GA, USA, 2017.

2. Goodrum, F.; Caviness, K.; Zagallo, P. Human cytomegalovirus persistence. Cell. Microbiol. 2012, 14, $644-655$. [CrossRef]

3. Bate, S.L.; Dollard, S.C.; Cannon, M.J. Cytomegalovirus seroprevalence in the United States: The national health and nutrition examination surveys, 1988-2004. Clin. Infect. Dis. 2010, 50, 1439-1447. [CrossRef]

4. Pawelec, G.; McElhaney, J.E.; Aiello, A.E.; Derhovanessian, E. The impact of CMV infection on survival in older humans. Curr. Opin. Immunol. 2012, 24, 507-511. [CrossRef]

5. Richardson, A. Is breast cancer caused by late exposure to a common virus? Med. Hypotheses 1997, 48, 491-497. [CrossRef]

6. Kocak, E.D.; Sherwin, J.C.; Hall, A.J. Cytomegalovirus disease in immunocompetent adults. Med. J. Aust. 2015, 202, 419. [CrossRef]

7. Jean Beltran, P.M.; Cristea, I.M. The life cycle and pathogenesis of human cytomegalovirus infection: Lessons from proteomics. Expert Rev. Proteom. 2014, 11, 697-711. [CrossRef] [PubMed]

8. Rana, R.; Biegalke, B.J. Human cytomegalovirus UL34 early and late proteins are essential for viral replication. Viruses 2014, 6, 476-488. [CrossRef]

9. Gibson, L.; Dooley, S.; Trzmielina, S.; Somasundaran, M.; Fisher, D.; Revello, M.G.; Luzuriaga, K. Cytomegalovirus (CMV) IE1- and pp65-specific CD8+ T cell responses broaden over time after primary CMV infection in infants. J. Infect. Dis. 2007, 195, 1789-1798. [CrossRef]

10. Cheng, S.; Caviness, K.; Buehler, J.; Smithey, M.; Nikolich-Zugich, J.; Goodrum, F. Transcriptome-wide characterization of human cytomegalovirus in natural infection and experimental latency. Proc. Natl. Acad. Sci. USA 2017, 114, E10586-E10595. [CrossRef] [PubMed]

11. Britt, W. Manifestations of human cytomegalovirus infection: Proposed mechanisms of acute and chronic disease. Curr. Top Microbiol. Immunol. 2008, 325, 417-470. [PubMed] 
12. Barton, E.S.; White, D.W.; Cathelyn, J.S.; Brett-McClellan, K.A.; Engle, M.; Diamond, M.S.; Miller, V.L.; Virgin, H.W.t. Herpesvirus latency confers symbiotic protection from bacterial infection. Nature 2007, 447, 326-329. [CrossRef]

13. Che, J.W.; Daniels, K.A.; Selin, L.K.; Welsh, R.M. Heterologous immunity and persistent murine cytomegalovirus infection. J. Virol. 2017, 91. [CrossRef]

14. Rahbar, A.; Bostrom, L.; Lagerstedt, U.; Magnusson, I.; Soderberg-Naucler, C.; Sundqvist, V.A. Evidence of active cytomegalovirus infection and increased production of IL-6 in tissue specimens obtained from patients with inflammatory bowel diseases. Inflamm. Bowel Dis. 2003, 9, 154-161. [CrossRef]

15. Frantzeskaki, F.G.; Karampi, E.S.; Kottaridi, C.; Alepaki, M.; Routsi, C.; Tzanela, M.; Vassiliadi, D.A.; Douka, E.; Tsaousi, S.; Gennimata, V.; et al. Cytomegalovirus reactivation in a general, nonimmunosuppressed intensive care unit population: Incidence, risk factors, associations with organ dysfunction, and inflammatory biomarkers. J. Crit. Care 2015, 30, 276-281. [CrossRef] [PubMed]

16. Tu, W.; Rao, S. Mechanisms Underlying T Cell Immunosenescence: Aging and cytomegalovirus infection. Front Microbiol. 2016, 7, 2111. [CrossRef]

17. McDevitt, L.M. Etiology and impact of cytomegalovirus disease on solid organ transplant recipients. Am. J. Health Syst. Pharm. 2006, 63, S3-S9. [CrossRef] [PubMed]

18. Jain, M.; Duggal, S.; Chugh, T.D. Cytomegalovirus infection in non-immunosuppressed critically ill patients. J. Infect. Dev. Ctries 2011, 5, 571-579. [CrossRef] [PubMed]

19. El Shazly, D.F.; Bahnassey, A.A.; Omar, O.S.; Elsayed, E.T.; Al-Hindawi, A.; El-Desouky, E.; Youssef, H.; Zekri, A.N. Detection of human cytomegalovirus in malignant and benign breast tumors in Egyptian women. Clin. Breast Cancer 2018, 18, e629-e642. [CrossRef]

20. Herbein, G.; Kumar, A. The oncogenic potential of human cytomegalovirus and breast cancer. Front. Oncol. 2014, 4, 230. [CrossRef]

21. Harkins, L.E.; Matlaf, L.A.; Soroceanu, L.; Klemm, K.; Britt, W.J.; Wang, W.; Bland, K.I.; Cobbs, C.S. Detection of human cytomegalovirus in normal and neoplastic breast epithelium. Herpesviridae 2010, 1, 8. [CrossRef]

22. Taher, C.; de Boniface, J.; Mohammad, A.A.; Religa, P.; Hartman, J.; Yaiw, K.C.; Frisell, J.; Rahbar, A.; Soderberg-Naucler, C. High prevalence of human cytomegalovirus proteins and nucleic acids in primary breast cancer and metastatic sentinel lymph nodes. PLoS ONE 2013, 8, e56795. [CrossRef]

23. El-Shinawi, M.; Mohamed, H.T.; Abdel-Fattah, H.H.; Ibrahim, S.A.; El-Halawany, M.S.; Nouh, M.A.; Schneider, R.J.; Mohamed, M.M. Inflammatory and non-inflammatory breast cancer: A potential role for detection of multiple viral DNAs in disease progression. Ann. Surg. Oncol. 2016, 23, 494-502. [CrossRef] [PubMed]

24. Cui, J.; Wang, Q.; Wang, H.B.; Wang, B.; Li, L. Protein and DNA evidences of HCMV infection in primary breast cancer tissues and metastatic sentinel lymph nodes. Cancer Biomark. 2018, 21, 769-780. [CrossRef]

25. Taher, C.; Frisk, G.; Fuentes, S.; Religa, P.; Costa, H.; Assinger, A.; Vetvik, K.K.; Bukholm, I.R.; Yaiw, K.C.; Smedby, K.E.; et al. High prevalence of human cytomegalovirus in brain metastases of patients with primary breast and colorectal cancers. Transl. Oncol. 2014, 7, 732-740. [CrossRef]

26. Tsai, J.H.; Hsu, C.S.; Tsai, C.H.; Su, J.M.; Liu, Y.T.; Cheng, M.H.; Wei, J.C.; Chen, F.L.; Yang, C.C. Relationship between viral factors, axillary lymph node status and survival in breast cancer. J. Cancer Res. Clin. Oncol. 2007, 133, 13-21. [CrossRef]

27. Stoddart, C.A.; Cardin, R.D.; Boname, J.M.; Manning, W.C.; Abenes, G.B.; Mocarski, E.S. Peripheral blood mononuclear phagocytes mediate dissemination of murine cytomegalovirus. J. Virol. 1994, 68, 6243-6253.

28. Yang, Z.; Brindley, D.N.; Hemmings, D.G.; University of Alberta, Edmonton, AB, Canada. Unpublished data. 2018.

29. Herbein, G. The Human cytomegalovirus, from oncomodulation to oncogenesis. Viruses 2018, 10. [CrossRef] [PubMed]

30. Von Laer, D.; Meyer-Koenig, U.; Serr, A.; Finke, J.; Kanz, L.; Fauser, A.A.; Neumann-Haefelin, D.; Brugger, W.; Hufert, F.T. Detection of cytomegalovirus DNA in CD34+ cells from blood and bone marrow. Blood 1995, 86, 4086-4090. [PubMed]

31. Mendelson, M.; Monard, S.; Sissons, P.; Sinclair, J. Detection of endogenous human cytomegalovirus in CD34+ bone marrow progenitors. J. Gen. Virol. 1996, 77 Pt 12, 3099-3102. [CrossRef]

32. Hahn, G.; Jores, R.; Mocarski, E.S. Cytomegalovirus remains latent in a common precursor of dendritic and myeloid cells. Proc. Natl. Acad. Sci. USA 1998, 95, 3937-3942. [CrossRef] 
33. Soderberg-Naucler, C.; Streblow, D.N.; Fish, K.N.; Allan-Yorke, J.; Smith, P.P.; Nelson, J.A. Reactivation of latent human cytomegalovirus in CD14(+) monocytes is differentiation dependent. J. Virol. 2001, 75, 7543-7554. [CrossRef]

34. Reeves, M.B.; MacAry, P.A.; Lehner, P.J.; Sissons, J.G.; Sinclair, J.H. Latency, chromatin remodeling, and reactivation of human cytomegalovirus in the dendritic cells of healthy carriers. Proc. Natl. Acad. Sci. USA 2005, 102, 4140-4145. [CrossRef] [PubMed]

35. Shiao, S.L.; Ganesan, A.P.; Rugo, H.S.; Coussens, L.M. Immune microenvironments in solid tumors: New targets for therapy. Genes Dev. 2011, 25, 2559-2572. [CrossRef]

36. Simon, C.O.; Seckert, C.K.; Dreis, D.; Reddehase, M.J.; Grzimek, N.K. Role for tumor necrosis factor alpha in murine cytomegalovirus transcriptional reactivation in latently infected lungs. J. Virol. 2005, 79, 326-340. [CrossRef]

37. Hammer, Q.; Romagnani, C. About training and memory: NK-Cell adaptation to viral infections. Adv. Immunol. 2017, 133, 171-207. [CrossRef] [PubMed]

38. Guy, C.T.; Cardiff, R.D.; Muller, W.J. Induction of mammary tumors by expression of polyomavirus middle T oncogene: A transgenic mouse model for metastatic disease. Mol. Cell. Biol. 1992, 12, 954-961. [CrossRef] [PubMed]

39. Aslakson, C.J.; Miller, F.R. Selective events in the metastatic process defined by analysis of the sequential dissemination of subpopulations of a mouse mammary tumor. Cancer Res. 1992, 52, 1399-1405. [PubMed]

40. Ewens, A.; Mihich, E.; Ehrke, M.J. Distant metastasis from subcutaneously grown E0771 medullary breast adenocarcinoma. Anticancer Res. 2005, 25, 3905-3915.

41. Davie, S.A.; Maglione, J.E.; Manner, C.K.; Young, D.; Cardiff, R.D.; MacLeod, C.L.; Ellies, L.G. Effects of $\mathrm{FVB} / \mathrm{NJ}$ and $\mathrm{C} 57 \mathrm{Bl} / 6 \mathrm{~J}$ strain backgrounds on mammary tumor phenotype in inducible nitric oxide synthase deficient mice. Transgenic Res. 2007, 16, 193-201. [CrossRef]

42. MacManiman, J.D.; Meuser, A.; Botto, S.; Smith, P.P.; Liu, F.; Jarvis, M.A.; Nelson, J.A.; Caposio, P. Human cytomegalovirus-encoded pUL7 is a novel CEACAM1-like molecule responsible for promotion of angiogenesis. MBio 2014, 5, e02035. [CrossRef]

43. Dumortier, J.; Streblow, D.N.; Moses, A.V.; Jacobs, J.M.; Kreklywich, C.N.; Camp, D.; Smith, R.D.; Orloff, S.L.; Nelson, J.A. Human cytomegalovirus secretome contains factors that induce angiogenesis and wound healing. J. Virol. 2008, 82, 6524-6535. [CrossRef]

44. Folkman, J. Angiogenesis in cancer, vascular, rheumatoid and other disease. Nat. Med. 1995, 1, $27-31$. [CrossRef]

45. Friedl, P.; Wolf, K. Plasticity of cell migration: A multiscale tuning model. J. Cell. Biol. 2010, 188, 11-19. [CrossRef]

46. Hanahan, D.; Weinberg, R.A. Hallmarks of cancer: The next generation. Cell 2011, 144, 646-674. [CrossRef]

47. Canalis, E. Interleukin-1 has independent effects on deoxyribonucleic acid and collagen synthesis in cultures of rat calvariae. Endocrinology 1986, 118, 74-81. [CrossRef] [PubMed]

48. Goldring, M.B.; Krane, S.M. Modulation by recombinant interleukin 1 of synthesis of types I and III collagens and associated procollagen mRNA levels in cultured human cells. J. Biol. Chem. 1987, 262, 16724-16729. [PubMed]

49. Iwamoto, G.K.; Konicek, S.A. Cytomegalovirus immediate early genes upregulate interleukin-6 gene expression. J. Investig. Med. 1997, 45, 175-182. [PubMed]

50. Radunovic, M.; Tomanovic, N.; Novakovic, I.; Boricic, I.; Milenkovic, S.; Dimitrijevic, M.; Radojevic-Skodric, S.; Bogdanovic, L.; Basta-Jovanovic, G. Cytomegalovirus induces Interleukin-6 mediated inflammatory response in salivary gland cancer. J. BUON 2016, 21, 1530-1536. [PubMed]

51. Cao, H.; Zhang, J.; Liu, H.; Wan, L.; Zhang, H.; Huang, Q.; Xu, E.; Lai, M. IL-13/STAT6 signaling plays a critical role in the epithelial-mesenchymal transition of colorectal cancer cells. Oncotarget 2016, 7, 61183-61198. [CrossRef]

52. Benesch, M.G.; Tang, X.; Maeda, T.; Ohhata, A.; Zhao, Y.Y.; Kok, B.P.; Dewald, J.; Hitt, M.; Curtis, J.M.; McMullen, T.P.; et al. Inhibition of autotaxin delays breast tumor growth and lung metastasis in mice. FASEB J. 2014, 28, 2655-2666. [CrossRef] [PubMed]

53. Kurz, S.K.; Reddehase, M.J. Patchwork pattern of transcriptional reactivation in the lungs indicates sequential checkpoints in the transition from murine cytomegalovirus latency to recurrence. J. Virol. 1999, 73, 8612-8622. [PubMed] 
54. Tang, X.; Benesch, M.G.; Dewald, J.; Zhao, Y.Y.; Patwardhan, N.; Santos, W.L.; Curtis, J.M.; McMullen, T.P.; Brindley, D.N. Lipid phosphate phosphatase-1 expression in cancer cells attenuates tumor growth and metastasis in mice. J. Lipid Res. 2014, 55, 2389-2400. [CrossRef] [PubMed]

55. Junqueira, L.C.; Bignolas, G.; Brentani, R.R. Picrosirius staining plus polarization microscopy, a specific method for collagen detection in tissue sections. Histochem. J. 1979, 11, 447-455. [CrossRef] [PubMed]

56. Cook, C.H.; Trgovcich, J.; Zimmerman, P.D.; Zhang, Y.; Sedmak, D.D. Lipopolysaccharide, tumor necrosis factor alpha, or interleukin-1beta triggers reactivation of latent cytomegalovirus in immunocompetent mice. J. Virol. 2006, 80, 9151-9158. [CrossRef] [PubMed]

57. Koffron, A.J.; Hummel, M.; Patterson, B.K.; Yan, S.; Kaufman, D.B.; Fryer, J.P.; Stuart, F.P.; Abecassis, M.I. Cellular localization of latent murine cytomegalovirus. J. Virol. 1998, 72, 95-103. [PubMed]

58. IBM Corporation. IBM SPSS Statistics for Windows; Version 25.0.; IBM Corporation: Armonk, NY, USA, 2017.

(C) 2019 by the authors. Licensee MDPI, Basel, Switzerland. This article is an open access article distributed under the terms and conditions of the Creative Commons Attribution (CC BY) license (http://creativecommons.org/licenses/by/4.0/). 